\title{
Legionella pneumophila couples fatty acid flux to microbial differentiation and virulence
}

Rachel L. Edwards, ${ }^{1}$ Zachary D. Dalebroux ${ }^{2}$ and Michele S. Swanson ${ }^{1,2 *}$

${ }^{1}$ Cellular and Molecular Biology Program and

${ }^{2}$ Department of Microbiology and Immunology,

University of Michigan Medical School, Ann Arbor, MI,

USA.

\section{Summary}

During its life cycle, Legionella pneumophila alternates between at least two phenotypes: a resilient, infectious form equipped for transmission and a replicative cell type that grows in amoebae and macrophages. Considering its versatility, we postulated that multiple cues regulate $L$. pneumophila differentiation. Beginning with a Biolog Phenotype MicroArray screen, we demonstrate that excess short-chain fatty acids (SCFAs) trigger replicative cells to cease growth and activate their panel of transmissive traits. To co-ordinate their response to SCFAs, L. pneumophila utilizes the LetA/LetS twocomponent system, but not phosphotransacetylase or acetyl kinase, two enzymes that generate highenergy phosphate intermediates. Instead, the stringent response enzyme SpoT appears to monitor fatty acid biosynthesis to govern transmission trait expression, as an altered distribution of acylated acyl carrier proteins correlated with the SpoT-dependent differentiation of cells treated with either excess SCFAs or the fatty acid biosynthesis inhibitors cerulenin and 5-(tetradecyloxy)-2-furoic acid. We postulate that, by exploiting the stringent response pathway to couple cellular differentiation to its metabolic state, L. pneumophila swiftly acclimates to stresses encountered in its host or the environment, thereby enhancing its overall fitness.

\section{Introduction}

Legionella pneumophila is a promiscuous, Gram-negative pathogen commonly found in freshwater systems. In

Accepted 22 December, 2008. *For correspondence. E-mail mswanson@umich.edu; Tel. (+1) 734647 7295; Fax (+1) 734764 3562. these environments, L. pneumophila efficiently parasitizes many different species of amoebae and protozoa (Fields et al., 2002). Moreover, Legionella can establish biofilms in both natural and potable water systems, which serve as reservoirs of contamination (Fields et al., 2002). If susceptible individuals aspirate bacteria-laden aerosols, the pathogen can colonize the alveolar macrophages to cause the severe pneumonia Legionnaires' disease. Due to the disparate conditions under which L. pneumophila can survive, the bacteria must utilize mechanisms to monitor their milieu and swiftly acclimate to their surroundings.

To tolerate environmental fluctuations, many bacteria alter their cellular physiology and morphology, a process known as differentiation. The sexually transmitted bacterium Chlamydia trachomatis alternates between an extracellular, metabolically inert elementary body required for transmission and an intracellular, metabolically active reticulate body that undergoes repeated cycles of cell division (Samuel et al., 2003; Abdelrahman and Belland, 2005). Likewise, the aetiologic agent of human $Q$ fever, Coxiella burnetii, differentiates between a replicative large cell variant and a resilient small cell variant (Heinzen et al., 1999). Within biofilm communities, the opportunistic pathogen Pseudomonas aeruginosa alternates between distinct motile and non-motile cell types (Purevdorj-Gage et al., 2005). By employing cellular differentiation, bacterial pathogens can evade host defence mechanisms and promote self-preservation.

Ground-breaking work by Rowbotham revealed that, within amoebae, $L$. pneumophila also exhibits two distinct phenotypes: a non-motile, thin-walled replicative form and a motile, thick-walled infectious form that contains stores of an energy-rich polymer (Rowbotham, 1986). Corroborating these early findings, subsequent genetic and molecular studies determined that the replicative and transmissive phases of the $L$. pneumophila life cycle are reciprocal (Byrne and Swanson, 1998; Hammer and Swanson, 1999; Alli et al., 2000; Watarai et al., 2001; Wieland et al., 2002; Molofsky and Swanson, 2003). The current model suggests that when phagocytic cells engulf transmissive L. pneumophila, the bacteria avoid lysosomal degradation by establishing vacuoles isolated from the endosomal network, a process mediated by the Dot/ Icm type IV secretion system and its substrates, as well as 
by vesicles shed from the outer membrane (Berger and Isberg, 1993; Berger et al., 1994; Joshi et al., 2001; Segal et al., 2005; Fernandez-Moreira et al., 2006). If conditions in the vacuole are favourable, the RNA-binding protein CsrA and the sRNA chaperone Hfq repress transmissive traits, enabling L. pneumophila to replicate profusely (Fettes et al., 2001; Molofsky and Swanson, 2003; McNealy et al., 2005). Once nutrient supplies are exhausted, replication halts, and the progeny initiate a global change in their physiology known as the stringent response (Hammer and Swanson, 1999; Zusman et al., 2002). This pathway generates the alarmone ppGpp, which co-ordinates bacterial differentiation. In particular, a major shift in the L. pneumophila transcriptional profile is mediated by alternative sigma factors, while the LetA/ LetS two-component system relieves CsrA repression on transmissive traits (Hammer and Swanson, 1999; Hammer et al., 2002; Molofsky and Swanson, 2003; Bruggemann et al., 2006). As a consequence, L. pneumophila expresses a panel of traits that are vital for dissemination, including cytotoxicity, motility and lysosome evasion (Bachman and Swanson, 2001; 2004a,b; Hammer et al., 2002; Lynch et al., 2003; Jacobi et al., 2004). In addition, L. pneumophila may further develop into the highly resilient and infectious mature intracellular form under defined conditions (Faulkner and Garduno, 2002; Garduno et al., 2002). Eventually, the exhausted host cell lyses, releasing transmissive L. pneumophila into the environment, which can then initiate subsequent rounds of infection.

Amino acid concentrations appear to be a critical metabolic cue, as fluctuations in their availability alter the developmental state of the microbe. For example, intracellular L. pneumophila rely on PhtA, a transporter of the Major Facilitator Superfamily, to gauge whether the threonine supply is sufficient to sustain growth (Sauer et al., 2005). Furthermore, macrophages require the amino acid transporter SLC1A5 to support replication of intracellular L. pneumophila (Wieland et al., 2005). Studies of broth cultures predict that when amino acid supplies are depleted, uncharged tRNAs accumulate, and the stringent response enzyme RelA produces the ppGpp signalling molecule which triggers L. pneumophila differentiation (Hammer and Swanson, 1999; Zusman et al., 2002).

Because Legionella persist in diverse environments, we postulated that signals other than amino acids also induce their differentiation. Indeed, for transmission between macrophages, L. pneumophila requires SpoT (Dalebroux et al., 2009), a second ppGpp synthetase known to equip Escherichia coli to generate the alarmone in response to a variety of stresses, such as phosphate starvation or inhibition of fatty acid biosynthesis (Seyfzadeh et al., 1993; Gong et al., 2002; Zusman et al., 2002; Magnusson et al., 2005; Battesti and Bouveret, 2006). By screening hundreds of metabolites via Biolog Phenotype MicroArrays, and then applying a series of pharmacological, biochemical and genetic tests, we determined that, in response to perturbations in fatty acid biosynthesis, replicative L. pneumophila rely on SpoT to activate the stringent response pathway and co-ordinately express transmissive traits, thereby coupling phase differentiation to their metabolic state.

\section{Results}

\section{Biolog Phenotype MicroArrays identify novel cues of} L. pneumophila differentiation

To identify signals that trigger L. pneumophila differentiation, we employed Biolog Phenotype MicroArrays to screen various sources of carbon, nitrogen, sulphur and phosphorous. Exponential (E) L. pneumophila carrying a gfp reporter for flagellin, a marker of transmissive bacteria (Table 1), were cultured in the plates, and their relative fluorescence was monitored. Of the 387 compounds screened, only 22 (6\%) induced flaAgfp expression prematurely (Table 2). Among these were deoxyadenosine, deoxyribose, 2-deoxy-D-glucose 6-phosphate, dihydroxyacetone, nitrite, hydroxylamine, parabanic acid and methionine-alanine dipeptide. However, the predominant class of compounds (12 of 22) was carboxylic acids. In particular, the four short-chain fatty acids (SCFAs) - formic, acetic, propionic and butyric acid, and the medium chain fatty acid caprioc acid all triggered flaAgfp expression. Also eliciting a positive response were two detergents, Tween 20 and Tween 80; however, both detergents also contain the carboxylic acid groups lauric and oleic acid respectively. Indeed, when exposed to $5 \mathrm{mM}$ lauric acid, a 12 carbon carboxylic acid, L. pneumophila also stopped replicating and expressed flaAgfp (data not shown). However, the response to lauric acid was slower and less robust than to the SCFAs, likely due to the requirement for receptormediated transport across the L. pneumophila membrane and perhaps the time needed for the fatty acid to be degraded via $\beta$-oxidation. Interestingly, high concentrations of SCFAs inhibit the growth of many microorganisms (Bohnhoff et al., 1964), including L. pneumophila (Warren and Miller, 1979). Moreover, acetate, propionate and butyrate regulate Salmonella typhimurium invasion gene expression in vitro at concentrations that correlate with their abundance in the intestinal tract (Lawhon et al., 2002). Therefore, we postulated that $L$. pneumophila monitors SCFAs to co-ordinate its life cycle.

\section{Excess short chain fatty acids inhibit L. pneumophila growth and induce motility}

Acetic and propionic acid, which were identified in the Phenotype MicroArray screen, were selected for further 
Table 1. Bacterial strains and plasmids.

\begin{tabular}{|c|c|c|}
\hline Strain or plasmid & Relevant genotype/phenotype & Reference or source \\
\hline \multicolumn{3}{|l|}{ Strains } \\
\hline \multicolumn{3}{|l|}{ E. coli } \\
\hline $\mathrm{DH} 5 \alpha$ & 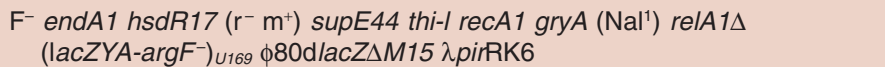 & Laboratory collection \\
\hline MB619 & DH5 $\alpha$ pGEM-T-PtaAckA2 & This work \\
\hline MB681 & DH5 $\alpha$ pGEM-T-PtaAckA2::Kan & This work \\
\hline \multicolumn{3}{|l|}{ L. pneumophila } \\
\hline MB110 & Lp02 wild-type; thyA hsdR rpsL & Berger and Isberg (1993) \\
\hline MB355 & pflaG & Hammer and Swanson (1999) \\
\hline MB413 & letA-22::kan & Hammer et al. (2002) \\
\hline MB414 & letA-22::kan pflaG & Hammer et al. (2002) \\
\hline MB416 & letS-36::kan & Hammer et al. (2002) \\
\hline MB417 & letS-36::kan pflaG & Hammer et al. (2002) \\
\hline MB641 & pta ackA2::kan & This work \\
\hline MB682 & pta ackA2::kan pflaG & This work \\
\hline MB684 & relA::kan pflaG & Dalebroux et al. (2009) \\
\hline MB685 & relA::gent spoT::kan pflaG & Dalebroux et al. (2009) \\
\hline MB696 & relA::kan & Dalebroux et al. (2009) \\
\hline MB697 & relA::gent spoT::kan & Dalebroux et al. (2009) \\
\hline \multicolumn{3}{|l|}{ Plasmids } \\
\hline pGEM-T & $\begin{array}{l}\text { Multiple cloning site within coding region of } \beta \text {-lactamase } \alpha \text { fragment } \\
\text { linearized with single-T overhangs; } 3 \mathrm{~kb} ; \mathrm{Amp}^{\mathrm{R}}\end{array}$ & Promega \\
\hline pflaG & $\begin{array}{l}150 \mathrm{bp} f \mathrm{fl} A \text { promoter fragment fused to green fluorescent protein encodes } \\
\text { thymidylate synthetase; } 10.5 \mathrm{~kb} ; \mathrm{Amp}^{\mathrm{R}}\end{array}$ & Hammer and Swanson (1999) \\
\hline pGEM-T-PtaAckA2 & $\begin{array}{l}\text { pGEM-T containing } 3.3 \mathrm{~kb} \text { pta ackA2 locus PCR amplified from Lp02 } \\
\text { chromosome and ligated into T overhangs; } 6.3 \mathrm{~kb} ; \mathrm{Amp}^{R}\end{array}$ & This work \\
\hline pUC4K & pUC4 containing $1.3 \mathrm{~kb}$ kanamycin cassette & Pharmacia \\
\hline pGEM-T-PtaAckA2::Kan & $\begin{array}{l}\text { pGEM-T-PtaAckA2 with } 1.3 \mathrm{~kb} \text { kanamycin cassette inserted between } \\
\text { Xmal and Nhel sites in the pta ackA2 open reading frame resulting in } \\
\text { a } 1.8 \mathrm{~kb} \text { deletion }\end{array}$ & This work \\
\hline
\end{tabular}

analysis as previous data indicate that both regulate virulence genes in $S$. typhimurium, albeit with opposite effects (Lawhon et al., 2002). As predicted, when E cultures were treated with either $10 \mathrm{mM}$ acetic or propionic acid, L. pneumophila immediately stopped replicating (Fig. 1A and $\mathrm{C}$ ) and activated the flaA promoter (Fig. 1B and D). The growth inhibition of $L$. pneumophila treated with the SCFAs was not attributed to a loss in viability, as judged by enumerating colony-forming units (cfu) (data not shown). In contrast, control cultures supplemented with water did not induce the flaA promoter or halt replication until the transition to the post-exponential (PE) phase, which occurred at $9 \mathrm{~h}$ (corresponds to $\mathrm{OD}_{600} \approx 3.4$; Fig. 1 , circles). Titration experiments analysing a range from 2.5 to $20 \mathrm{mM}$ demonstrated that $10 \mathrm{mM}$ SCFAs was optimal, as lower concentrations failed to significantly activate the flaA promoter or inhibit growth (data not shown).

To determine whether the response by L. pneumophila to SCFAs was a consequence of alterations in $\mathrm{pH}, \mathrm{E}$ bacteria were instead treated with two inorganic acids. When added to concentrations of $1.25-20 \mathrm{mM}$, neither hydrochloric nor perchloric acid triggered growth inhibition or induction of the flaAgfp promoter (Fig. 1E and F; data not shown). Moreover, the $\mathrm{pH}$ of $L$. pneumophila cultures supplemented with acetic or propionic acid did not differ significantly from those supplemented with water, nor did the $\mathrm{pH}$ of the treated cultures vary detectably over the course of the experiment (data not shown). Finally, when E cultures were supplemented with non-acidic forms of acetate, $L$. pneumophila stopped replicating and activated the flagellin promoter. For example, when supplemented with $10 \mathrm{mM}$ calcium acetate for $6 \mathrm{~h}$, E cultures showed a 28-fold induction of flaAgfp when compared with water control (data not shown). Therefore, L. pneumophila respond to a signal generated by SCFAs that is distinct from $\mathrm{pH}$.

\section{Fatty acid supplementation stimulates L. pneumophila differentiation}

We next investigated whether SCFAs trigger other L. pneumophila transmissive phase phenotypes, including motility, cytotoxicity to phagocytic cells, avoidance of lysosomal degradation and sodium sensitivity (Byrne and Swanson, 1998). As expected from the flaAgfp data (Fig. 1), microscopic examination revealed that $10 \mathrm{mM}$ SCFAs induced motility (Table 3). Also, after supplementation with either acetic or propionic acid, E phase L. pneumophila became as cytotoxic to macrophages as PE control cultures (Fig. 2A). Importantly, the addition of SCFAs alone was not 
Table 2. Compounds that trigger premature differentiation in L. pneumophila.

\begin{tabular}{|c|c|c|}
\hline Compound $^{a}$ & Biolog plate & Mean $\mathrm{FC}^{\mathrm{b}}$ at $6 \mathrm{~h}$ \\
\hline \multicolumn{3}{|l|}{ Carboxylic acids } \\
\hline Formic acid & PM1 & $7.3 \pm 0.6$ \\
\hline Acetic acid & PM1 & $1.8 \pm 0.2$ \\
\hline Propionic acid & PM1 & $4.8 \pm 1.9$ \\
\hline Butyric acid & PM2A & $3.3 \pm 1.9$ \\
\hline$\alpha$-Ketovaleric acid & PM2A & $1.9 \pm 0.7$ \\
\hline Caproic acid & PM2A & $7.2 \pm 1.4$ \\
\hline Itaconic acid & PM2A & $2.4 \pm 0.8$ \\
\hline Sorbic acid & PM2A & $2.6 \pm 0.4$ \\
\hline 4-hydroxybenzoic acid & PM2A & $1.8 \pm 0.4$ \\
\hline m-hydroxy phenyl acetic acid & PM1 & $3.8 \pm 2.1$ \\
\hline p-hydroxy phenyl acetic acid & PM1 & $2.9 \pm 1.4$ \\
\hline Monomethyl succinate & PM1 & $4.7 \pm 0.6$ \\
\hline \multicolumn{3}{|l|}{ Detergents } \\
\hline Polyoxyethylene sorbitan monolaurate (Tween 20) & PM5 & $3.2 \pm 1.2$ \\
\hline Polyoxyethylene sorbitan monooleate (Tween 80) & PM1 & $1.4 \pm 0.1$ \\
\hline \multicolumn{3}{|l|}{ Other } \\
\hline 2-Deoxy-D-glucose 6-phosphate & PM4A & $2.0 \pm 1.3$ \\
\hline Deoxyadenosine & PM1 & $2.0 \pm 0.2$ \\
\hline Deoxyribose & PM2A & $2.3 \pm 0.4$ \\
\hline Dihydroxyacetone & PM2A & $2.7 \pm 0.4$ \\
\hline Hydroxylamine & PM3B & $1.7 \pm 0.2$ \\
\hline Met-Ala dipeptide & PM3B & $1.6 \pm 0.4$ \\
\hline Nitrite & PM3B & $5.1 \pm 1.8$ \\
\hline Parabanic acid & PM3B & $1.5 \pm 0.3$ \\
\hline
\end{tabular}

a. Approximate concentrations: 5-20 mM carbon sources, 2-5 mM nitrogen sources, and 0.1-2 mM phosphorus and sulphur sources.

b. FC indicates the fold change \pm SD in fluorescence between the compound and the negative control well on the Phenotype MicroArray plate.

cytotoxic (Table 3, letA and letS mutants; data not shown). Further, although only $15 \%$ of $E$ phase control L. pneumophila avoided degradation, $>50 \%$ of those exposed to acetic or propionic acid remained intact (Fig. 2B). Finally, $10 \mathrm{mM}$ acetic or propionic acid also triggered sodium sensitivity in E phase microbes (Fig. 2C). Thus, our Biolog screen accurately predicted that exposure to $10 \mathrm{mM}$ SCFAs induces the L. pneumophila transmissive phenotype. Moreover, our studies support previous data that indicate that the flaAgfp reporter is a valid marker of L. pneumophila differentiation (Hammer and Swanson, 1999; Sauer et al., 2005; Bruggemann et al., 2006). Accordingly, we next investigated two potential modes of action: excess SCFA may either generate high-energy intermediates that activate two-component phosphorelay systems or instead alter fatty acid metabolism.

To respond to fatty acids, L. pneumophila requires the LetA/LetS two-component system, but not generation of acetyl-phosphate and propionyl-phosphate

The L. pneumophila two-component system LetA/LetS regulates all known transmissive phase phenotypes (Hammer et al., 2002 Lynch et al., 2003; Broich et al., 2006; Shi et al., 2006). To discern whether the response of $L$. pneumophila to SCFAs depends on this signal transduction system, we exploited let $A$ and letS mutants. When confronted with SCFAs, the letA and letS mutants resembled wild-type (WT) L. pneumophila by restricting their growth (Table 3). However, L. pneumophila required the LetA/LetS system to induce flagellin expression in response to $10 \mathrm{mM}$ acetic acid (Fig. $3 \mathrm{~A}$ ) and also the stronger inducer propionic acid, albeit to a lesser degree (Fig. 3B). The two-component system was also largely required for expression of four other transmissive traits: motility, cytotoxicity, lysosome avoidance and sodium sensitivity (Table 3). Therefore, when L. pneumophila encounters a sudden increase in SCFAs, a pathway that includes LetA/LetS co-ordinates bacterial differentiation.

The response regulators of many two-component systems can use the high-energy intermediates acetylphosphate and propionyl-phosphate to catalyse their own phosphorylation (Boucher et al., 1994; Lawhon et al., 2002; Wolfe, 2005). Therefore, we tested whether exogenous acetic or propionic acid are first converted to acetyl- and propionyl-phosphate before activating the LetA/LetS signal transduction system by analysing a L. pneumophila mutant that lacks the two enzymes that synthesize the phosphate intermediates, phosphotransacetylase and acetyl kinase, encoded by the pta and ackA2 genes respectively (McCleary et al., 1993; Wolfe, 2005). By monitoring the activity of the flagellin promoter, it was evident that neither the phosphotransacetylase nor the acetyl kinase enzyme was needed for L. pneumophila 
A

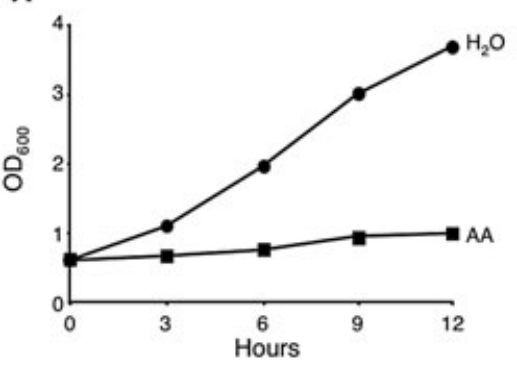

C

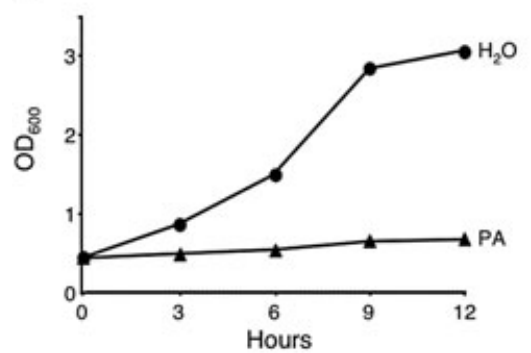

E

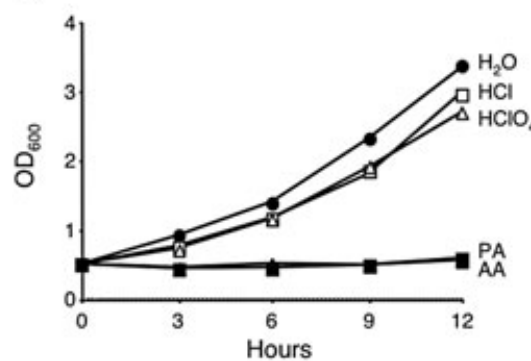

B

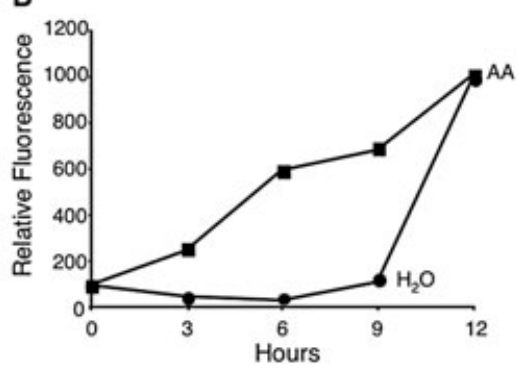

D

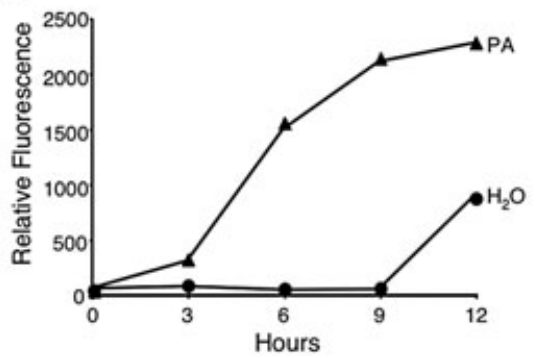

$\mathbf{F}$

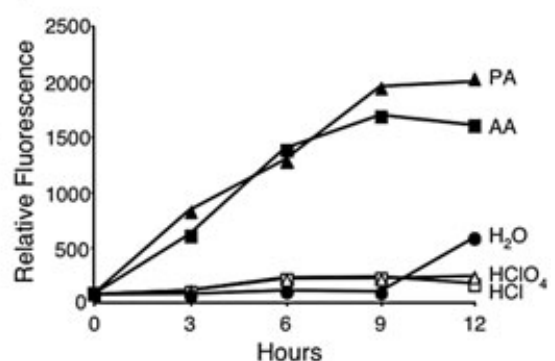

Fig. 1. Growth inhibition and the premature expression of motility are specific to fatty acid addition. WT L. pneumophila carrying the flaAgfp reporter construct were cultured to the $E$ phase and then supplemented with $10 \mathrm{mM}$ acetic acid (AA; closed squares), propionic acid (PA; closed triangles), hydrochloric acid $(\mathrm{HCl}$; open squares) or perchloric acid $\left(\mathrm{HClO}_{4}\right.$; open triangles). At the times indicated, the optical density (A, C, E) and relative fluorescence $(B, D, F)$ of samples were analysed. For all experiments, $\mathrm{E}$ cultures supplemented with water $\left(\mathrm{H}_{2} \mathrm{O}\right.$; closed circles) served as a negative control. Shown are representative graphs from three or more independent experiments in which the mean fold change in fluorescence at $9 \mathrm{~h} \pm$ SEM when compared with $\mathrm{H}_{2} \mathrm{O}$ control was: $\mathrm{AA}=15.7 \pm 3.1 ; \mathrm{PA}=50.5 \pm 15.2$; $\mathrm{HCl}=0.87 \pm 0.48 ; \mathrm{HClO}_{4}=1.0 \pm 1.0$. to differentiate when confronted by excess acetic or propionic acid (Fig. 4). Thus, unlike Salmonella and Bordetella (Boucher et al., 1994; Lawhon et al., 2002), SCFAs trigger L. pneumophila differentiation by a mechanism other than generating acetyl- and propionyl-phosphate intermediates to activate LetA/LetS.

\section{Perturbations in fatty acid biosynthesis trigger}

\section{L. pneumophila differentiation}

To begin to test the hypothesis that SCFA supplements impinge upon either fatty acid degradation or biosynthesis, we tested whether acetic and propionic acid trigger L. pneumophila differentiation when the irreversible conversion of acetyl-CoA to malonyl-CoA is blocked. In mammalian cells, the competitive inhibitor 5-(tetradecyloxy)-2furoic acid (TOFA) blocks the acetyl-CoA carboxylase (ACC) complex (accA, Ipg0785; accB, Ipg0463; accC, Ipg0462 and $a c c D$, Ipg1341) and prevents acetate from being incorporated into fatty acids (Fig. 5A; Panek et al., 1977; Cook et al., 1978; McCune and Harris, 1979; Magnuson et al., 1993; Pizer et al., 2000; Zhou et al., 2003). Accordingly, malonyl-CoA levels in the cell are signifi- cantly reduced and fatty acid biosynthesis is halted. When cultures were simultaneously supplemented with SCFAs and TOFA, the majority of bacteria failed to differentiate (Fig. 5B and C). When treated with TOFA alone, L. pneumophila did not differentiate, although their growth was restricted and viability was maintained, as the number of cfu was similar between 0 and $24 \mathrm{~h}$ after TOFA treatment (data not shown). Because activity of the ACC complex appeared to be required for SCFAs to initiate L. pneumophila differentiation, we deduced that addition of $10 \mathrm{mM}$ acetic or propionic acid likely affects the fatty acid biosynthetic pathway.

As an independent test of this model, we exploited the antibiotic cerulenin, which has been well documented in E. coli to irreversibly block two key fatty acid enzymes, FabB (Ipg0102, Ipg0361 and Ipg0362) and FabF (Ipg1397; Fig. 5A; Vance et al., 1972; Omura, 1976; Buttke and Ingram, 1978; Ulrich et al., 1983). Rather than depleting malonyl-CoA, cerulenin causes this precursor to accumulate in the cell (Heath and Rock, 1995). When E phase WT L. pneumophila were treated with $0.5 \mu \mathrm{g} \mathrm{ml}^{-1}$ cerulenin, bacterial replication stopped (data not shown) and the flaA promoter was activated (Fig. 5D). This 
Table 3. Phenotypic response of letA and letS mutants $3 \mathrm{~h}$ after fatty acid supplementation.

\begin{tabular}{|c|c|c|c|c|c|c|}
\hline Strain & Culture conditions & $\begin{array}{l}\text { Growth } \\
\text { inhibition }\end{array}$ & Motility $^{b}$ & Cytotoxicityc & Degradation $^{d}$ & $\mathrm{Na}$ sensitivity ${ }^{e}$ \\
\hline WT & $\begin{array}{l}\text { PE Control } \\
\mathrm{E}+\mathrm{H}_{2} \mathrm{O} \\
\mathrm{E}+\text { acetic acid } \\
\mathrm{E}+\text { propionic acid }\end{array}$ & $\begin{array}{l}+ \\
- \\
+ \\
+\end{array}$ & $\begin{array}{l}++ \\
- \\
++ \\
++\end{array}$ & $\begin{array}{l}+(9 \pm 2 \%) \\
-(68 \pm 15 \%) \\
+(16 \pm 3 \%) \\
+(23 \pm 8 \%)\end{array}$ & $\begin{array}{l}+(82 \pm 2 \%) \\
-(16 \pm 2 \%) \\
+(52 \pm 5 \%) \\
+(62 \pm 5 \%)\end{array}$ & $\begin{array}{c}+(0.3 \pm 0.2 \%) \\
-(85 \pm 13 \%) \\
+(8 \pm 2 \%) \\
+(9 \pm 3 \%)\end{array}$ \\
\hline letA & $\begin{array}{l}\text { PE control } \\
E+\mathrm{H}_{2} \mathrm{O} \\
\mathrm{E}+\text { acetic acid } \\
\mathrm{E}+\text { propionic acid }\end{array}$ & $\begin{array}{l}+ \\
- \\
+ \\
+\end{array}$ & $\begin{array}{l}- \\
- \\
- \\
-\end{array}$ & $\begin{array}{l}-(74 \pm 13 \%) \\
-(78 \pm 12 \%) \\
-(65 \pm 2 \%) \\
-(76 \pm 9 \%)\end{array}$ & $\begin{array}{l}-(38 \pm 5 \%) \\
-(18 \pm 3 \%) \\
-(27 \pm 3 \%) \\
-(35 \pm 7 \%)\end{array}$ & $\begin{array}{c}-(48 \pm 21 \%) \\
-(118 \pm 16 \%) \\
-(14 \pm 7 \%) \\
-(18 \pm 7 \%)\end{array}$ \\
\hline lets & $\begin{array}{l}\text { PE control } \\
E+\mathrm{H}_{2} \mathrm{O} \\
\mathrm{E}+\text { acetic acid } \\
\mathrm{E}+\text { propionic acid }\end{array}$ & $\begin{array}{l}+ \\
- \\
+ \\
+\end{array}$ & $\begin{array}{l}- \\
- \\
- \\
-\end{array}$ & $\begin{array}{l}-(82 \pm 10 \%) \\
-(81 \pm 8 \%) \\
-(71 \pm 15 \%) \\
-(69 \pm 16 \%)\end{array}$ & $\begin{array}{l}-(47 \pm 5 \%) \\
-(18 \pm 3 \%) \\
-(29 \pm 2 \%) \\
-(41 \pm 3 \%)\end{array}$ & $\begin{array}{c}-(64 \pm 6 \%) \\
-(105 \pm 4 \%) \\
-(22 \pm 10 \%) \\
-(26 \pm 20 \%)\end{array}$ \\
\hline
\end{tabular}

a. Growth of $L$. pneumophila was monitored by measuring the $\mathrm{OD}_{600}$ of the cultures $3 \mathrm{~h}$ after supplementation. Although letA and letS cultures supplemented with fatty acids do not display PE phenotypes, bacterial growth is completely inhibited. (+) indicates growth inhibition, while (-) indicates normal growth kinetics. Data represent at least three independent experiments.

b. Motility was assessed by phase-contrast microscopy and is based on numerous independent observations. (-) indicates cultures that were $<10 \%$ motile $(+)$ indicates $10-25 \%$ motility $(++)$ indicates $25-75 \%$ motility, and $(+++)$ indicates high levels of directed motility $(>75 \%)$.

c. Cytotoxicity of $L$. pneumophila for macrophages was assessed by measuring the reduction of alamarBlue following a $1 \mathrm{~h}$ incubation. Data points that fell within a moi range of 5-10 were pooled. (+) indicates that less than $50 \%$ of the macrophages were viable, whereas (-) represents greater than $50 \%$ macrophage viability. In parentheses, the mean percent of viable macrophages \pm SEM is shown from at least three independent experiments performed in triplicate.

d. The per cent of bacteria that remain intact following a $2 \mathrm{~h}$ incubation within macrophages was determined by fluorescence microscopy. $(+)$ indicates that $>50 \%$ of the bacteria were able to avoid degradation and (-) indicates that $<50 \%$ of the bacteria avoided degradation. Data represent the mean \pm SEM from at least three independent experiments performed in duplicate.

e. The per cent of sodium sensitive bacteria was calculated by comparing cfu of cultures plated onto media with and without $100 \mathrm{mM} \mathrm{NaCl}$. (+) indicates $<10 \%$ inhibition and $(-)$ indicates $>10 \%$ inhibition. The values represent the mean \pm SEM for at least three independent experiments performed in duplicate.

response was largely dependent on the LetA/LetS twocomponent system because WT cultures treated with cerulenin exhibited a $54 \pm 15$-fold change in fluorescence when compared with the DMSO control sample at $6 \mathrm{~h}$, whereas the signal from let $A$ and letS cultures increased only $12 \pm 2.7$-fold and $16 \pm 3.9$-fold respectively (data reported for each strain are the means \pm SEM in three independent experiments). In eukaryotic cells, the simultaneous addition of cerulenin and TOFA decreases malonyl-CoA levels and blocks fatty acid biosynthesis
A

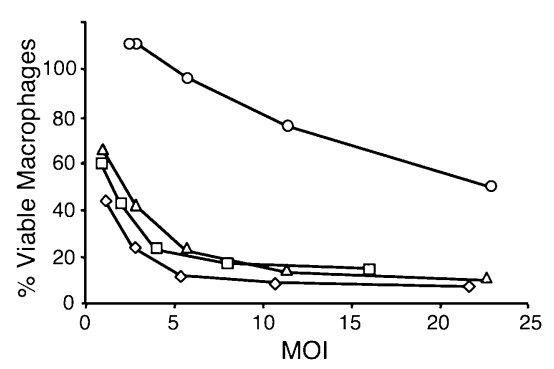

C

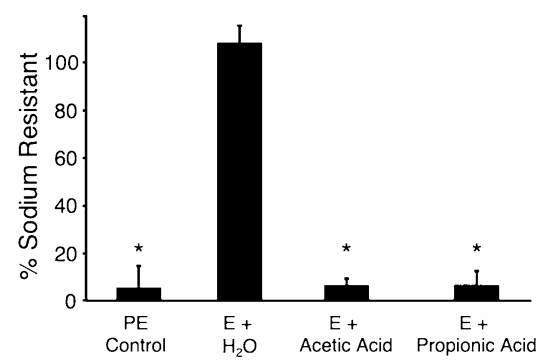

B

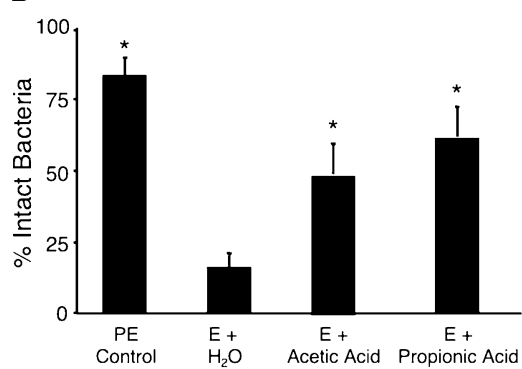

Control $\quad \mathrm{H}_{2} \mathrm{O} \quad$ Acetic Acid Propionic Acid

Fig. 2. Fatty acid supplementation of WT L. pneumophila induces the early expression of multiple transmissive phase phenotypes. A. Macrophage viability was assessed by alamarBlue reduction following a $1 \mathrm{~h}$ incubation with PE (diamonds) or E cultures supplemented with water (circles), acetic acid (squares) or propionic acid (triangles). Shown is a representative graph from three independent experiments preformed in triplicate.

B. Lysosome evasion following a $2 \mathrm{~h}$ incubation was quantified by fluorescence microscopy as the per cent of intact bacteria. Displayed are the means from duplicate samples in three independent experiments. Error bars indicate SD and asterisks designate significant differences $(P<0.01)$ when compared with water control.

C. The mean percentage of sodium-resistant bacteria \pm SD was calculated from duplicate samples in three independent experiments. Asterisks denote statistically significant differences $(P<0.01)$ when compared with water control. 
A

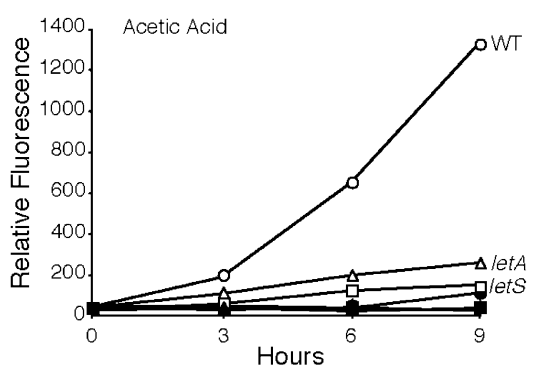

B

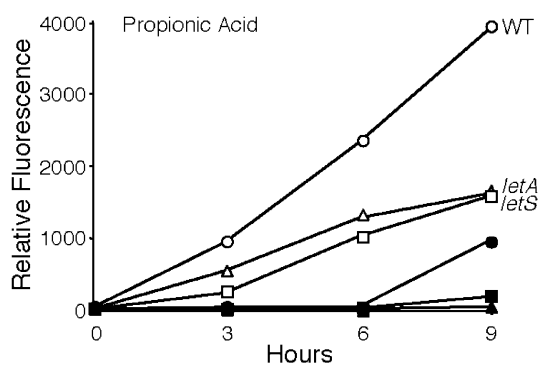

Fig. 3. The LetA/LetS signal transduction system is required for full induction of premature motility. E phase WT (circles), letA (triangles) or letS (squares) L. pneumophila containing the flaAgfp reporter were supplemented with water (closed symbols), $10 \mathrm{mM}$ acetic acid (open symbols; A) or $10 \mathrm{mM}$ propionic acid (open symbols; B), and their fluorescence analysed at the times indicated. Shown are representative graphs from three independent experiments in which the mean fold change in fluorescence at $6 \mathrm{~h} \pm \mathrm{SEM}$ when compared with $\mathrm{H}_{2} \mathrm{O}$ control was: $\mathrm{WT}+$ acetic acid $=39.7 \pm 15.7$; let $A+$ acetic acid $=6.2 \pm 2.5$; letS + acetic acid $=6.7 \pm 2.3$; WT + propionic acid $=77.0 \pm 8.5$; let $A+$ propionic acid $=59.0 \pm 10.0 ;$ letS + propionic acid $=52.2 \pm 13.6$.

(Pizer et al., 2000). Whereas cerulenin activates the L. pneumophila flaA promoter, cultures treated with both cerulenin and TOFA did not differentiate (Fig. 5E), implicating malonyl-CoA accumulation as a prerequisite for the stress response. Taken together, the effects of both SCFA supplementation and the pharmacological inhibitors of

\section{A}

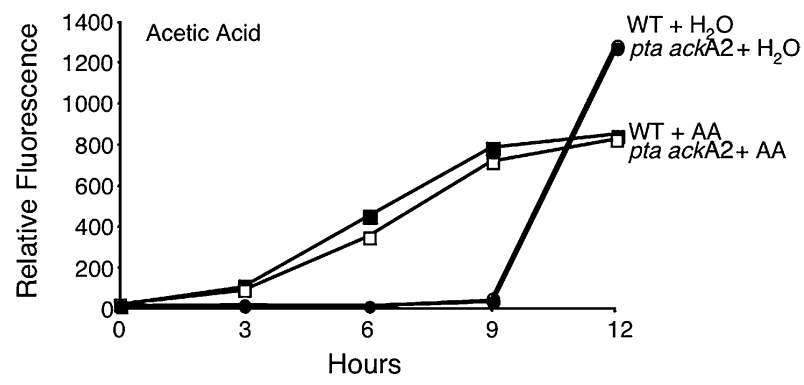

B

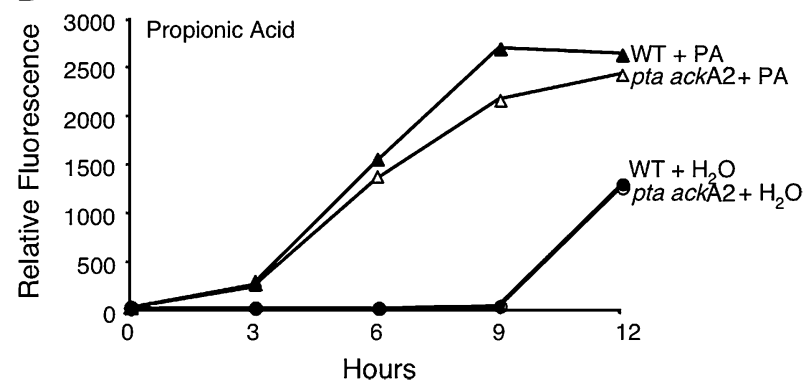

Fig. 4. Induction of motility by fatty acid addition is independent of pta ackA2. E phase broth cultures of WT (closed symbols) or pta ackA2 (open symbols) L. pneumophila containing pflaG were supplemented with water $\left(\mathrm{H}_{2} \mathrm{O}\right.$; circles), $10 \mathrm{mM}$ acetic acid $(\mathrm{A} ; \mathrm{AA}$ : squares), or $10 \mathrm{mM}$ propionic acid (B; PA: triangles), and their relative fluorescence assessed by fluorometry at $3 \mathrm{~h}$ intervals.

Shown are representative graphs from three experiments in which the mean fold change in fluorescence at $9 \mathrm{~h} \pm$ SEM when compared with $\mathrm{H}_{2} \mathrm{O}$ control was: $\mathrm{WT}+\mathrm{AA}=11.9 \pm 4.6$; pta ackA2 + AA $=11.9 \pm 5.1 ; \mathrm{WT}+\mathrm{PA}=42.0 \pm 17.0$; pta ackA2 $+\mathrm{PA}=37.5 \pm 14.1$ particular biosynthetic enzymes indicate that, when fatty acid biosynthesis is disrupted, L. pneumophila differentiates to the transmissive phase. Moreover, although it is well documented that in mammalian cells TOFA inhibits the ACC complex (Panek et al., 1977; McCune and Harris, 1979), this is the first indication that TOFA might elicit a similar response in microbes.

Short chain fatty acid supplements alter the profile of acylated acyl carrier proteins

A critical component of fatty acid and lipid biosynthesis is acyl carrier protein (ACP). In E. coli, once ACP is modified by a $4^{\prime}$-phosphopantetheine group, the small, acidic protein carries the growing fatty acid chain through successive rounds of elongation (Magnuson et al., 1993). To ascertain by an independent, biochemical approach whether SCFA supplementation alters the L. pneumophila fatty acid biosynthetic pathway, we analysed their acylACP pools.

When E cultures were supplemented with $10 \mathrm{mM}$ acetic or propionic acid for $3 \mathrm{~h}$, the profiles of acyl-ACPs were significantly different from those supplemented with water (Fig. 6). In particular, cultures treated with the SCFAs resembled the PE control, as similar ACP bands were depleted. A similar pattern was observed after treatment with cerulenin (Fig. 6). Therefore, these biochemical data are consistent with the model that flux in fatty acid biosynthesis triggers L. pneumophila differentiation.

\section{Alterations in the fatty acid biosynthetic pathway stimulates the stringent response}

Many microbes produce ppGpp from GTP to adapt to nutritional and metabolic stresses such as deprivation of amino acids, carbon, iron, phosphorous and fatty acids (Srivatsan and Wang, 2008). Moreover, a regulatory role 
A
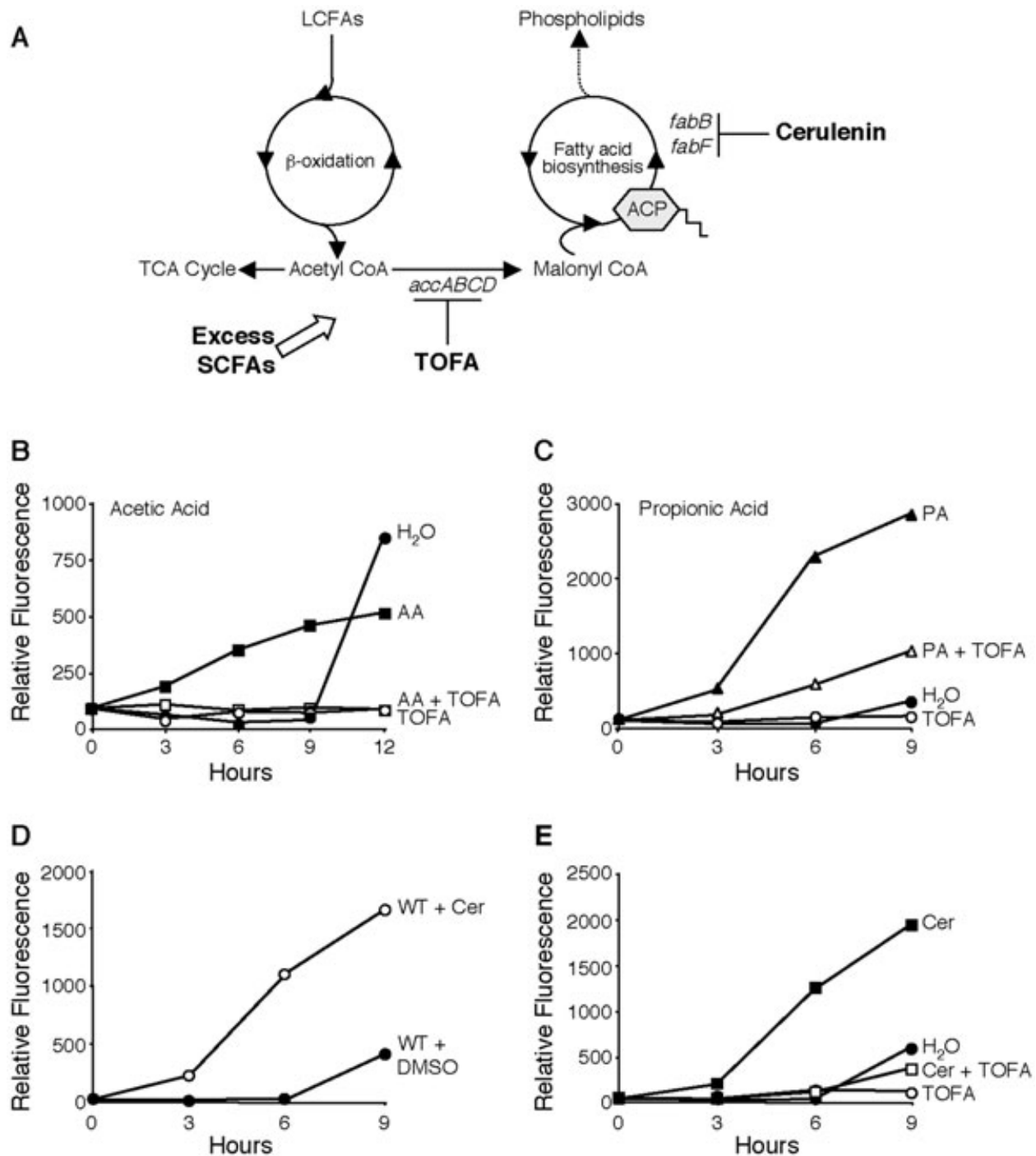

Fig. 5. Alterations in fatty acid biosynthesis induce L. pneumophila differentiation.

A. Schematic of fatty acid metabolism indicating where TOFA and cerulenin inhibitors act. LCFA, long-chain fatty acid.

$\mathrm{B}$ and $\mathrm{C}$. Inhibition of the conversion of acetyl-CoA to malonyl-CoA abrogates the early differentiation that is triggered by fatty acid supplementation.

B. E cultures containing pflaG were supplemented with $10 \mathrm{mM}$ acetic acid (AA; squares) with (open shapes) or without (closed shapes) the acetyl-CoA carboxylase inhibitor TOFA ( $5 \mathrm{\mu g} \mathrm{ml}^{-1}$; open circles), and the fluorescence was monitored over time. Identical cultures supplemented with water (closed circles) or DMSO (vehicle control, data not shown) were analysed as controls. The graph shown is representative of three independent experiments in which the mean fold change in fluorescence at $9 \mathrm{~h} \pm \mathrm{SEM}$ when compared with $\mathrm{H}_{2} \mathrm{O}$ control was: $\mathrm{AA}=10.2 \pm 4.1 ; \mathrm{TOFA}=2.4 \pm 1.4 ; \mathrm{AA}+\mathrm{TOFA}=1.6 \pm 0.4$

C. E cultures containing flaAgfp were supplemented with $10 \mathrm{mM}$ propionic acid (PA; triangles) with (open shapes) or without (closed shapes) TOFA ( $5 \mathrm{\mu g} \mathrm{ml}^{-1}$; open circles) and the fluorescence was monitored over time. Identical cultures supplemented with water (closed circles) or DMSO (vehicle control, data not shown) were analysed as controls. The graph shown is representative of four independent experiments in which the mean fold change in fluorescence at $6 \mathrm{~h} \pm \mathrm{SEM}$ when compared with $\mathrm{H}_{2} \mathrm{O}$ control was: $\mathrm{PA}=73.8 \pm 16.4$; $\mathrm{TOFA}=5.3 \pm 1.1$; $\mathrm{PA}+\mathrm{TOFA}=21.4 \pm 6.2$.

D. E cultures of WT L. pneumophila carrying the flaAgfp plasmid were supplemented with the fatty acid biosynthesis inhibitor, cerulenin (Cer, $0.5 \mu \mathrm{g} \mathrm{ml}^{-1}$; open circles) or vehicle control (DMSO, closed circles), and the relative fluorescence monitored over time. The graph shown is representative of four independent experiments in which the mean fold change in fluorescence at $6 \mathrm{~h} \pm$ SEM when compared with DMSO control was: $\mathrm{Cer}=65.0 \pm 8.1$.

E. E phase cultures of WT L. pneumophila containing pflaG were supplemented with cerulenin (Cer, $0.5 \mu \mathrm{g} \mathrm{ml}^{-1}$; closed squares) or cerulenin plus TOFA (open squares). Identical cultures treated with water $\left(\mathrm{H}_{2} \mathrm{O}\right.$; closed circles) or TOFA alone (open circles) are shown as controls. In three separate experiments, the mean fold change in fluorescence at $6 \mathrm{~h} \pm \mathrm{SEM}$ when compared with $\mathrm{H}_{2} \mathrm{O}$ control was: Cer $=39.8 \pm 10.1$; TOFA $=3.9 \pm 1.1$; Cer + TOFA $=6.8 \pm 2.0$. 
A

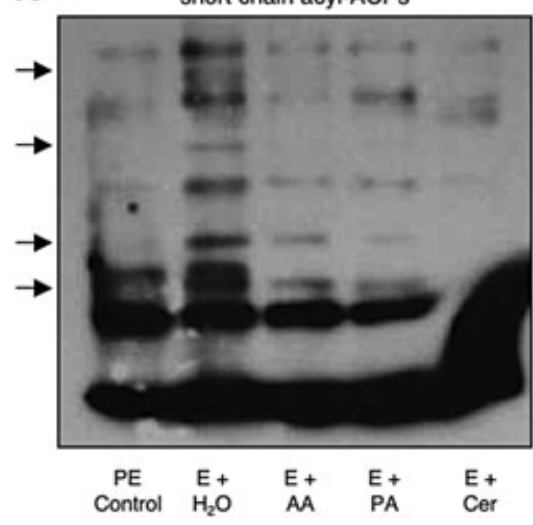

B

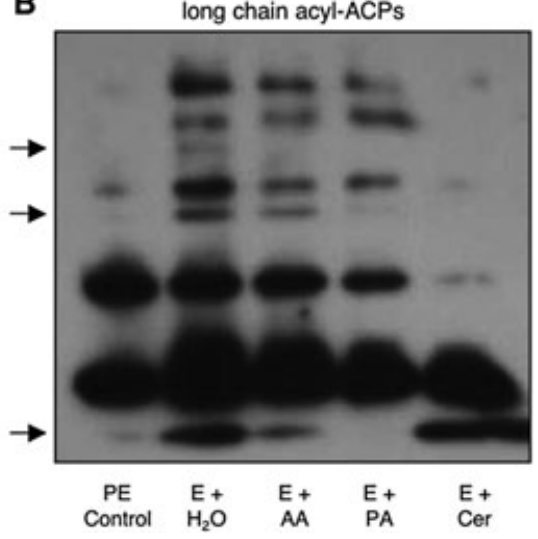

Fig. 6. Perturbations in fatty acid biosynthesis alter L. pneumophila acyl-ACP profiles. After incubating $\mathrm{E}$ phase

L. pneumophila for $3 \mathrm{~h}$ with water $\left(\mathrm{H}_{2} \mathrm{O}\right)$, acetic acid (AA), propionic acid (PA), or cerulenin (Cer), acyl-ACPs were purified, separated on $13 \%$ short-chain fatty acid $(A)$ or long-chain fatty acid (B) native polyacrylamide gels, and then detected by western analysis. Also shown are acyl-ACP pools from PE bacteria. Arrows denote protein bands that differ between the control and experimental samples. A film representative of three independent experiments is displayed. for ACP in the stringent response has recently been described in E. coli: SpoT directly interacts with the functional form of ACP, and single amino acid substitutions that disrupt this interaction abrogates SpoT-dependent ppGpp accumulation when fatty acid biosynthesis is inhibited (Battesti and Bouveret, 2006). Likewise, when fatty acid biosynthesis is inhibited pharmacologically in L. pneumophila, ppGpp accumulates by a mechanism that requires SpoT, but not RelA (Dalebroux et al., 2009). Therefore, we investigated whether L. pneumophila also accumulates ppGpp in response to excess SCFAs. When supplemented with either $10 \mathrm{mM}$ acetic or propionic acid, relA mutant cultures exhibited a trace level of ppGpp when compared with either the water or the relA spoT control (Fig. 7A; Table 1). The weak ppGpp signal detected in relA cells is consistent with that observed when WT and relA mutant L. pneumophila are treated with cerulenin, an inhibitor of fatty acid biosynthesis (Dalebroux et al., 2009; data not shown). Because the slight ppGpp accumulation by L. pneumophila exposed to SCFAs was not conclusive, we analysed genetically whether either the RelA or SpoT enzyme was required to co-ordinate this differentiation.

When E cultures were supplemented with either $10 \mathrm{mM}$ acetic or propionic acid, relA mutant $L$. pneumophila differentiated, similar to WT (Fig. 7B and C). In contrast, relA spoT mutants were unable to trigger the phenotypic switch (Fig. 7B and C). Together, our phenotypic, biochemical and genetic data presented both here and elsewhere (Dalebroux et al., 2009) demonstrate that, when fatty acid biosynthesis is perturbed, SpoT equips L. pneumophila to invoke the stringent response pathway to initiate a swift differentiation programme and rapidly adapt to metabolic stress.

\section{Discussion}

Because L. pneumophila persist within many diverse environments, we predicted that various metabolites cue its differentiation. By screening several hundred compounds via Phenotype MicroArrays, we identified 22 inducers of $L$. pneumophila differentiation and focused on carboxylic acids, which trigger a premature transition from the replicative to the transmissive phase (Fig. 2, Tables 2 and 3 and data not shown). Previous studies postulated that when amino acid concentrations are limiting, uncharged tRNAs accumulate and the RelA enzyme synthesizes ppGpp, an alarmone that activates the regulatory cascade that governs L. pneumophila differentiation (Fig. 8; Hammer and Swanson, 1999; Zusman et al., 2002). We have expanded this model by showing that SpoT co-ordinates transmission trait expression either when fatty acids are excessive or when their biosynthesis is perturbed, likely mediated by a regulatory interaction between SpoT and ACP (Figs 7 and 8; Seyfzadeh et al., 1993; Battesti and Bouveret, 2006; Dalebroux et al., 2009). Genetic data suggest that when SpoT can no longer bind ACP, L. pneumophila fails to differentiate in response to alterations in fatty acid biosynthesis (Dalebroux et al., 2009). Thus, we extend the paradigm of microbial differentiation by reporting that the stringent response machinery equips $L$. pneumophila to monitor both protein and fatty acid biosynthesis to regulate its virulence expression and govern transmission.

The mechanism by which bacteria detect fluctuations in fatty acid biosynthesis remains to be elucidated. In E. coli, SpoT might sense either an accumulation or a depletion of an intermediate in this biosynthetic pathway (DiRusso and Nystrom, 1998; Battesti and Bouveret, 2006). For Bacillus subtilis, a key regulator of lipid metabolism is malonylCoA, a molecule that may act as a signal during stress and starvation (Schujman et al., 2008). Similarly, E phase L. pneumophila immediately induce the flaAgfp reporter when treated with cerulenin (Fig. 5D), an inhibitor of fatty acid biosynthesis that causes malonyl-CoA to accumulate (Heath and Rock, 1995). On the other hand, TOFA, which is predicted to deplete the levels of malonyl-CoA present in the cell (Cook et al., 1978; McCune and Harris, 1979), 

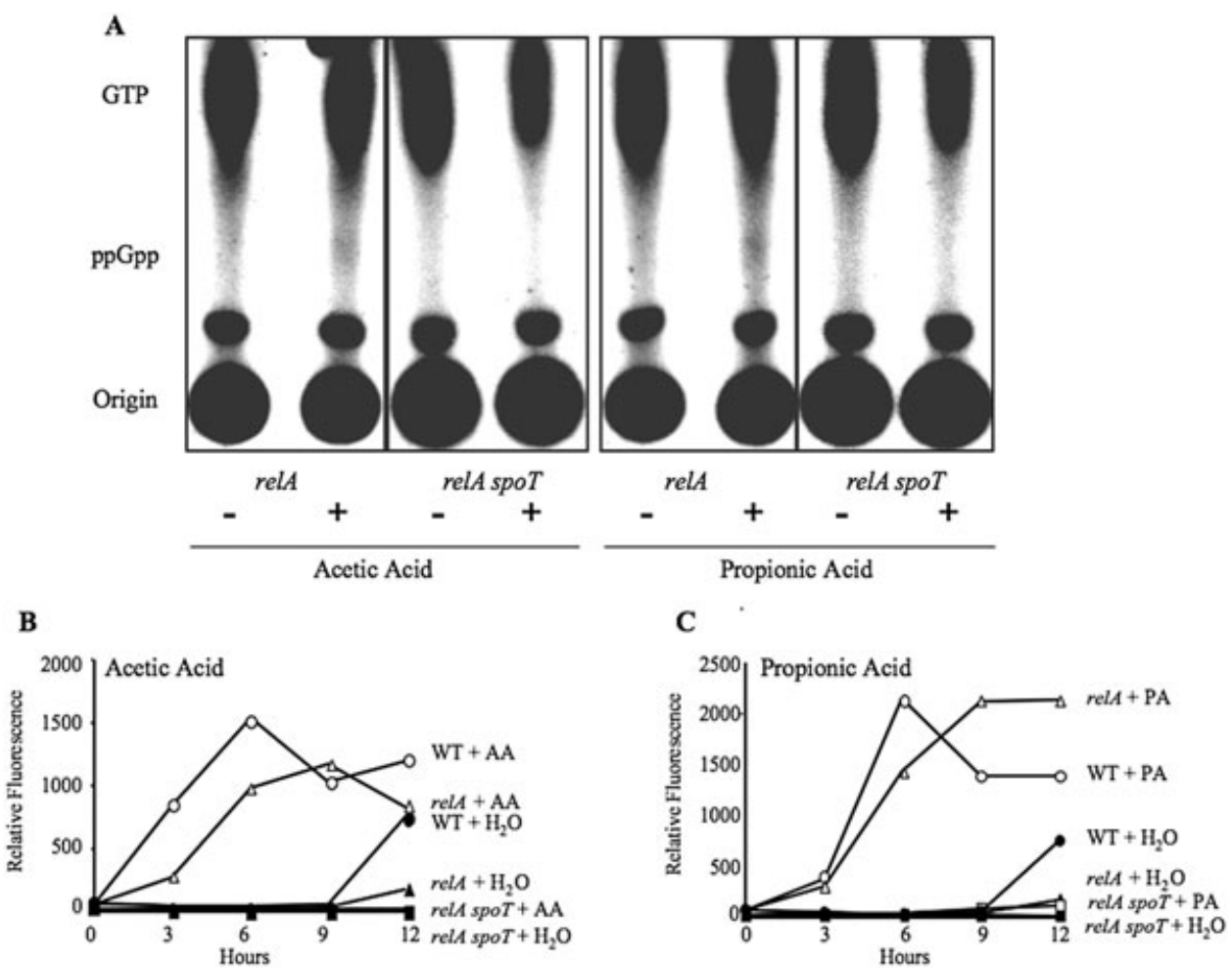

Fig. 7. L. pneumophila employs the stringent response to induce differentiation when fatty acid biosynthesis is altered. A. Perturbations in fatty acid biosynthesis trigger ppGpp production in the $\mathrm{E}$ phase. After labelling nucleotide pools with ${ }^{32} \mathrm{P}, \mathrm{E}$ cultures of relA and relA spoT mutant $L$. pneumophila were supplemented with water or $10 \mathrm{mM}$ SCFAs for $1.5 \mathrm{~h}$ to stimulate ppGpp synthesis. As ppGpp is synthesized from GTP and low levels of ppGpp are difficult to detect by TLC, the GTP pools are also indicated for each sample. Representative chromatograms from two or more independent experiments are shown for each condition.

B and C. L. pneumophila requires SpoT to sense SCFAs. E phase cultures of WT (circles), relA (triangles) or relA spoT (squares) L. pneumophila containing the flaAgfp reporter were supplemented with water (closed symbols), $10 \mathrm{mM}$ acetic acid (AA) (B; open symbols) or $10 \mathrm{mM}$ propionic acid (PA) (C; open symbols), and their fluorescence analysed at the times indicated. Shown are representative graphs from at least three independent experiments in which the mean fold change in fluorescence at $6 \mathrm{~h} \pm \mathrm{SEM}$ when compared with $\mathrm{H}_{2} \mathrm{O}$ controls was: $\mathrm{WT}+\mathrm{AA}=23.6 \pm 5.9 ; \mathrm{rel} A+\mathrm{AA}=30.7 \pm 10.2 ;$ relA spoT $+\mathrm{AA}=3.4 \pm 1.9 ; \mathrm{WT}+\mathrm{PA}=48.5 \pm 16.3 ;$ relA $+\mathrm{PA}=47.5 \pm 16.0 ;$ relA $s p o T+\mathrm{PA}=4.7 \pm 2.6$.

fails to stimulate $\mathrm{E}$ phase L. pneumophila to activate the flaA promoter (Fig. 5B, C and E). Therefore, L. pneumophila may monitor the levels of malonyl-CoA in the cell to regulate its phenotypic switch.

Alternatively, L. pneumophila may gauge the acyl chains attached to ACP. Perhaps the bacteria recognize either an accumulation or a depletion of one or more of the acyl-ACP species (e.g. Fig. 6) or an altered ratio of acyl-ACP to apo-ACP. In E. coli, there are numerous intermediates in the fatty acid biosynthetic pathway; accordingly, more detailed studies are needed to determine which, if any, intermediate(s) triggers L. pneumophila differentiation. L. pneumophila also encodes three putative ACPs (Ipg0359, Ipg1396 and Ipg2233) that are each predicted to be modified by 4'-phosphopantetheine (Magnuson et al., 1993). Our data do not address which $\mathrm{ACP}(\mathrm{s})$ is involved, as the specificity of the ACP antibody has not been determined (Fig. 6). Therefore, whether each ACP plays a unique or redundant role in the L. pneumophila life cycle remains to be determined.

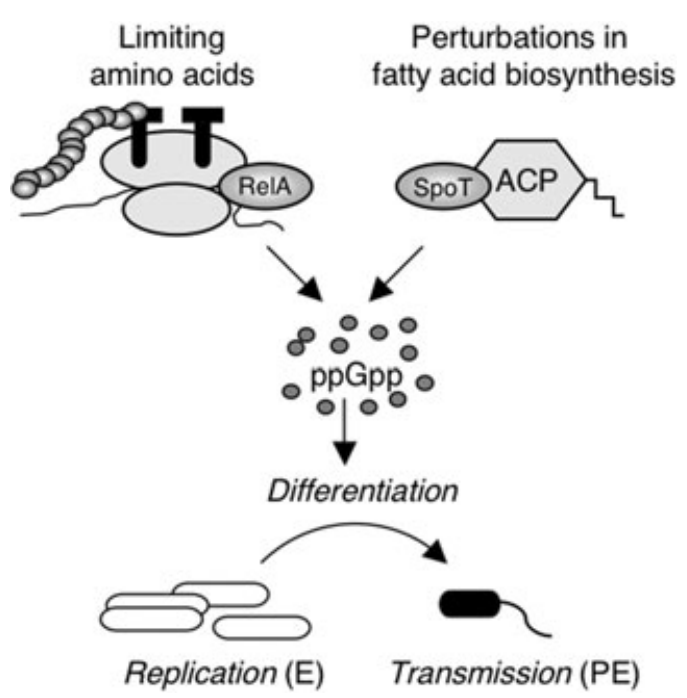

Fig. 8. L. pneumophila monitors flux in fatty acid biosynthesis to co-ordinate differentiation. See text for discussion of the model. 
By analogy to E. coli, we favour a model by which ppGpp-dependent sigma factor competition enables L. pneumophila to fine-tune its gene expression profile (reviewed by Bachman and Swanson, 2004a; Magnusson et al., 2005). The quantity of ppGpp observed in response to SCFAs and cerulenin is considerably less than that of PE bacteria (Fig. 7A; Dalebroux et al., 2009). This is consistent with the previous report that $E$. coli produces low levels of ppGpp in response to fatty acid starvation (Seyfzadeh et al., 1993). The difficulty in detecting ppGpp may reflect our labelling conditions: Due to its fastidious nature, a phosphate-limited medium to label nucleotides efficiently is not a viable option for L. pneumophila studies. Nevertheless, since every PE trait is induced when $E$ phase $L$. pneumophila are treated with excess SCFAs or cerulenin, even a modest level of ppGpp may be sufficient to trigger differentiation (Fig. 2, Table 3). Presumably, when fatty acid biosynthesis is altered, L. pneumophila produces a quantity of ppGpp sufficient to recruit to RNA polymerase the appropriate cohort of its six alternative sigma factors (Cazalet et al., 2004; Chien et al., 2004) to induce the PE traits that promote transmission to a new host and survival in the environment.

Several circumstances could alter the quantity of fatty acids in L. pneumophila's intracellular niche. When the TCA cycle does not operate completely, or when bacterial cells are flooded with excess carbon, microbes excrete acetate into their extracellular milieu (Wolfe, 2005). L. pneumophila also possesses lipolytic enzymes that may generate free fatty acids by degrading membranes of their own or their host (Hood et al., 1986; Archuleta et al., 2005). Alternatively, L. pneumophila may monitor external sources of fatty acids that are derived from the host plasma or phagosomal membranes. Consistent with this idea, within A/J mouse macrophages $L$. pneumophila replicate within a lysosomal compartment (Sturgill-Koszycki and Swanson, 2000), the site for membrane degradation. Interestingly, the alveolar macrophages of rats can ingest pulmonary surfactant, which is rich in phosphatidylcholine and phosphatidylglycerol (Grabner and Meerbach, 1991), two substrates for the phospholipase A secreted by L. pneumophila (Flieger et al., 2000). By this scenario, the accidental human host may exacerbate pathogenesis by stimulating synthesis of the transmission factor flagellin, which provokes a macrophage inflammatory cell death pathway (Molofsky et al., 2006; Ren et al., 2006; Vinzing et al., 2008).

Additional metabolites that are present on the Biolog arrays may also cue intracellular differentiation of $L$. pneumophila. First, the permeability of $L$. pneumophila for each of the compounds on the Phenotype MicroArrays is unknown. Also, the plates include one concentration of each compound, yet titration curves indicate that several inducers only trigger differentiation within a narrow con- centration range (data not shown). Indeed, nicotinic acid, which is present on Biolog plate PM5 at $10 \mu \mathrm{M}$, did not cause growth restriction or induction of the flaAgfp reporter, whereas $5 \mathrm{mM}$ nicotinic acid does trigger L. pneumophila differentiation, as judged by both microarray and phenotypic data (R.L. Edwards, M. Jules, C. Buchrieser and M.S. Swanson, unpublished).

Legionella pneumophila can monitor perturbations in fatty acid biosynthesis to regulate its differentiation in vitro, but whether SCFAs also induce transmission traits within vacuoles of phagocytic cells is not known, as their composition has yet to be elucidated. Although relA is dispensable for intracellular growth in both human macrophages and amoebae (Hammer and Swanson, 1999; Zusman et al., 2002), L. pneumophila does require SpoT not only for transmission between mouse macrophages, but also to differentiate from the replicative to the transmissive phase (Dalebroux et al., 2009). Therefore, L. pneumophila employs SpoT to monitor fatty acids or some other metabolite in macrophage vacuoles to govern its life cycle. By linking central metabolism to differentiation and virulence, $L$. pneumophila augments its fitness by adapting to fluctuating environments.

\section{Experimental procedures}

\section{Bacterial strains and cultures}

Legionella pneumophila strain Lp02 (thyA hsdR rpsL; MB110), a virulent thymine auxotroph, was the parent for all strains constructed (Berger and Isberg, 1993; Table 1). To obtain let $A$ and letS mutants lacking pflaG (MB413 and MB416 respectively), the mutant alleles from MB414 and MB417 were transferred onto the Lp02 chromosome by natural competence (Hammer et al., 2002). relA (MB696) and relA spoT (MB697) mutants were generated using standard techniques as described elsewhere (Dalebroux et al., 2009). To monitor the induction of the flaA promoter, the relA and relA spoT mutants were transformed with the pflaG plasmid to generate MB684 and MB685 respectively.

To construct a pta ackA2 (Ipg2261 and Ipg2262) deletion mutant, the $3.3 \mathrm{~kb}$ pta ackA2 locus was amplified from Lp02 genomic DNA using forward primer 5'-GCAACTCGTA TGCCATAC and reverse primer 5'-GTAAATCCATCGCTT TGGG. The PCR fragment was purified and ligated to pGEM-T (Promega), transformed into E. coli $\mathrm{DH} 5 \alpha$, and the resulting plasmid designated as pGEM-T-PtaAckA2 (MB619). A $1.8 \mathrm{~kb}$ region of the pta ackA2 open reading frame was removed by digestion with $\mathrm{Xmal}$ and $\mathrm{Nhel}$, and the remaining pGEM-T-PtaAckA2 fragment was blunted with Klenow and treated with Antarctic phosphatase (New England Biolabs). The $1.3 \mathrm{~kb}$ kanamycin-resistance cassette from pUC4K was removed via EcoRI digestion, blunted with Klenow and ligated into the digested pGEM-T-PtaAckA2 plasmid to create pGEM-T-PtaAckA2::Kan (MB681). After verification by $P C R$, the deletion/insertion alleles were transformed into Lp02 via natural competence and selected for by antibiotic resistance (Stone and Abu Kwaik, 1999). The 
desired chromosomal mutation was confirmed by PCR and the resulting strain designated as MB641. To monitor the induction of the flaA promoter by fluorometry, MB641 was transformed with pflaG. Two independent isolates were tested in fluorometry assays and found to be similar; MB682 data are displayed.

Bacteria were cultured at $37^{\circ} \mathrm{C}$ in $5 \mathrm{ml}$ aliquots of $\mathrm{N}$-(2acetamido)-2-aminoethanesulphonic acid (ACES; Sigma)buffered yeast extract (AYE) broth and supplemented with $100 \mu \mathrm{g} \mathrm{ml}^{-1}$ thymidine when necessary. Cultures having an optical density at $600 \mathrm{~nm}\left(\mathrm{OD}_{600}\right)$ of $0.5-0.85$ were defined as exponential (E), and those of $\mathrm{OD}_{600} 3.4-4.5$ as postexponential (PE). To obtain cfu, L. pneumophila were plated on ACES-buffered charcoal-yeast extract agar supplemented with $100 \mu \mathrm{g} \mathrm{ml}^{-1}$ thymidine (CYET) and incubated at $37^{\circ} \mathrm{C}$ for 4-5 days.

\section{Biolog Phenotype MicroArray analysis}

Phenotype MicroArray (PM) plates were purchased from Biolog (Hayward, CA; Table 2). One hundred microlitres of $E$ phase MB355 cultured in AYE media was added to each well of the Biolog plates, and the plates were incubated at $37^{\circ} \mathrm{C}$ while shaking. After 3 or $6 \mathrm{~h}, 100 \mu \mathrm{l}$ of each culture was transferred to black, clear-bottom tissue culture plates (Costar), and the relative fluorescence intensity was quantified using a Synergy HT microplate reader (Bio-Tek) using $485 \mathrm{~nm}$ excitation, $530 \mathrm{~nm}$ emission and sensitivity of 50 . Inducers were defined as having a 1.4-7.3 mean fold increase in fluorescence at $6 \mathrm{~h}$ when compared with the negative control well of the Biolog plates in at least three independent experiments.

\section{Fluorometry}

To monitor expression of the flagellin promoter, L. pneumophila strains containing the flaAgfp reporter plasmid pflaG were cultured in AYE media. At $\mathrm{OD}_{600}=0.50-0.85(T=0)$, the cultures were supplemented with $10 \mathrm{mM}$ acid, $0.5 \mu \mathrm{g} \mathrm{ml}^{-1}$ cerulenin (Sigma) or $5 \mu \mathrm{g} \mathrm{ml}^{-1}$ TOFA (Cayman Chemical). Cultures supplemented with water or DMSO served as negative and vehicle controls respectively. At the times indicated, culture cell density was measured as $\mathrm{OD}_{600}$. To analyse similar bacterial numbers, aliquots were collected by centrifugation, and the cell densities were normalized to $\mathrm{OD}_{600}=0.01$ in PBS. The fluorescence intensity of a $200 \mu \mathrm{l}$ aliquot was measured as described above.

\section{Motility}

To qualitatively assess motility, $10 \mu \mathrm{l}$ wet mounts of brothgrown L. pneumophila were prepared and immediately examined by phase-contrast microscopy. Relative motility levels were based on at least three independent observations of fields that contained several hundred microbes. A score of $(-)$ was assigned to cultures that were $<10 \%$ motile; (+) indicates cultures that were $10-25 \%$ motile; $(++)$ indicates cultures that were $25-75 \%$ motile; and $(+++)$ indicates that $>75 \%$ of the microbes within the fields displayed high levels of directed motility.

\section{Macrophages}

Macrophages isolated from femurs of female $\mathrm{A} / \mathrm{J}$ mice (Jackson Laboratory) were cultured in RPMI-1640 containing $10 \%$ heat-inactivated fetal bovine serum (RPMI/FBS; Gibco BRL) as described previously (Swanson and Isberg, 1995). Following a 7 day incubation in medium supplemented with L-cell supernatant, macrophages were plated at either $5 \times 10^{4}$ or $2.5 \times 10^{5}$ per well for cytotoxicity and degradation assays respectively.

\section{Cytotoxicity}

To measure contact-dependent cytotoxicity of $L$. pneumophila for macrophages, PE bacteria or E phase cultures supplemented with water or $10 \mathrm{mM}$ fatty acids for $3 \mathrm{~h}$ were added to monolayers at the indicated multiplicities of infection (moi). After centrifugation at $400 \mathrm{~g}$ for $10 \mathrm{~min}$ at $4^{\circ} \mathrm{C}$ (Molofsky et al., 2005), the cells were incubated for $1 \mathrm{~h}$ at $37^{\circ} \mathrm{C}$. To quantify macrophage viability, RPMI/FBS containing $10 \%$ alamarBlue (Trek Diagnostic Systems) was added to the monolayers for 6-12 h, and the reduction of the colorimetric dye was measured spectrophotometrically as described (Byrne and Swanson, 1998; Hammer and Swanson, 1999; Molofsky et al., 2005).

\section{Degradation}

The percentage of intracellular L. pneumophila that remained intact after a $2 \mathrm{~h}$ macrophage infection was quantified by fluorescence microscopy. Briefly, macrophages were plated at $2.5 \times 10^{5}$ onto coverslips in 24 well plates. Then, PE bacteria or $E$ phase microbes exposed to either water or $10 \mathrm{mM}$ fatty acids for $3 \mathrm{~h}$ were added to macrophage monolayers at a moi of $\sim 1$. The cells were centrifuged at $400 \mathrm{~g}$ for $10 \mathrm{~min}$ at $4^{\circ} \mathrm{C}$ and then incubated for $2 \mathrm{~h}$ at $37^{\circ} \mathrm{C}$. Uninternalized bacteria were removed by washing the monolayers with $3 \times 0.5 \mathrm{ml} \mathrm{RPMI} / \mathrm{FBS}$. Control experiments indicate that $<1 \%$ of the cell-associated bacteria are extracellular following the three RPMI/FBS washes (Bachman and Swanson, 2004a; and data not shown). Macrophages were then fixed, permeabilized and stained for L. pneumophila as described (Bachman and Swanson, 2001).

\section{Sodium sensitivity}

To calculate the percentage of L. pneumophila that are sensitive to sodium, PE bacteria or E cultures supplemented with either water or $10 \mathrm{mM}$ fatty acids for $3 \mathrm{~h}$ were plated onto CYET with or without $100 \mathrm{mM} \mathrm{NaCl}$. After 6 days at $37^{\circ} \mathrm{C}$, cfu were enumerated and the percentage of sodium sensitive microbes calculated as described (Byrne and Swanson, 1998).

\section{Analysis of acyl-ACPs}

For purification of acyl-ACPs, WT L. pneumophila were cultured to the $\mathrm{E}$ phase at $37^{\circ} \mathrm{C}$ on an orbital shaker in $250 \mathrm{ml}$ AYE containing $100 \mu \mathrm{g} \mathrm{ml}^{-1}$ thymidine. Upon reaching an 
$\mathrm{OD}_{600}$ between 0.5 and 0.85 , the cultures were supplemented with water, $10 \mathrm{mM}$ fatty acid or $0.5 \mu \mathrm{g} \mathrm{ml}^{-1}$ cerulenin and then cultured for an additional $3 \mathrm{~h}$. After collection by centrifugation at $4000 \mathrm{~g}$ for $20 \mathrm{~min}$ at $4^{\circ} \mathrm{C}$, the cell pellets were stored at $-80^{\circ} \mathrm{C}$. Once thawed on ice, the pellets were resuspended in $12.5 \mathrm{ml}$ ACP buffer (200 mM NaCl, $20 \mathrm{mM}$ Tris- $\mathrm{HCl}, \mathrm{pH}$, $1 \mathrm{mM}$ EDTA). To reduce protein degradation, one tablet of a protease inhibitor cocktail (Roche) was added to each $12.5 \mathrm{ml}$ suspension. Cells were lysed by sonication and the lysates cleared by centrifugation at $7000 \mathrm{~g}$ for $1 \mathrm{~h}$ at $4^{\circ} \mathrm{C}$. As $L$. pneumophila is predicted to contain three ACPs ranging from 8.6 to $15.3 \mathrm{kDa}$, large-molecular-weight proteins were removed from the lysates via $50 \mathrm{~K}$ and $30 \mathrm{~K}$ centrifugal filter devices (Amicon Ultra, Millipore \# UFC905024 and UFC903024 respectively). The remaining ACP fractions were concentrated with $5 \mathrm{~K}$ centrifugal filter devices (\# UFC800524), which also removed small-molecular-weight proteins and salts. The protein concentration of each sample was determined using the Bio-Rad Protein Assay, and samples were stored at $-20^{\circ} \mathrm{C}$. To visualize the profile of intracellular acyl-ACPs, $13 \%$ non-denaturing gels were prepared, and urea was added to either $0.5 \mathrm{M}$ or $2.5 \mathrm{M}$ for SCFA or long-chain fatty acid gels respectively (Rock and Cronan, 1981; Jackowski and Rock, 1983; Post-Beittenmiller et al., 1991). After electrophoresis in $192 \mathrm{mM}$ glycine, $25 \mathrm{mM}$ Tris buffer, samples were transferred to polyvinylidene difluoride membrane (Bio-Rad), and the membranes blocked in TBS-T (20 mM Tris- $\mathrm{HCl}, \mathrm{pH} 7.5,500 \mathrm{mM} \mathrm{NaCl}, 0.05 \%$ Tween 20) containing $5 \%$ non-fat milk. To detect the L. pneumophila ACP proteins, the membranes were probed with a primary antibody generated by E. coli ACP (gift from C.O. Rock, Memphis, TN) diluted 1:500 and a secondary goat anti-rabbit antibody conjugated to horseradish peroxidase (Pierce) diluted 1:8000 (Jackowski and Rock, 1983) and then developed with SuperSignal West Pico Chemiluminescent Substrate (Pierce).

\section{Detection of ppGpp}

Accumulation of the ppGpp signalling molecule in response to flux in fatty acid metabolism was detected by thin-layer chromatography (TLC) as described (Cashel, 1969; 1994; Hammer and Swanson, 1999). Briefly, E phase relA (MB696) and relA spoT (MB697) cultures were diluted to an $\mathrm{OD}_{600}=0.25$ and cultured at $37^{\circ} \mathrm{C}$ on a roller drum with approximately $100 \mu \mathrm{Ci} \mathrm{ml}{ }^{-1}$ carrier-free $\left[{ }^{32} \mathrm{P}\right]$-phosphoric acid (ICN Pharmaceuticals) for $6 \mathrm{~h}$, or two generation times. Next, cultures were supplemented with water, $10 \mathrm{mM}$ acetic acid or $10 \mathrm{mM}$ propionic acid and incubated for an additional $1.5 \mathrm{~h}$ at $37^{\circ} \mathrm{C}$. To extract the nucleotides, $50 \mu \mathrm{l}$ aliquots were removed from each culture and added to $13 \mathrm{M}$ formic acid and then incubated on ice for $15 \mathrm{~min}$. Samples were subjected to two freeze-thaw cycles and stored at $-80^{\circ} \mathrm{C}$ until used for chromatography. Formic acid extracts $(25 \mu \mathrm{l})$ were applied to a PEI-cellulose TLC plate $(20 \times 20)$ and developed with $1.5 \mathrm{M}$ $\mathrm{KH}_{2} \mathrm{PO}_{4}$, pH 3.4 as described (Cashel, 1969; 1994; Hammer and Swanson, 1999). TLC plates were exposed to autoradiography film for $72 \mathrm{~h}$ and developed in a phosphoimager. To monitor growth following water or fatty acid supplementation, optical densities were determined for non-radioactive cultures grown under identical conditions.

\section{Acknowledgements}

We thank Drs Sean Prigge and Kathryn T. Young for advice on electrophoresis of acyl-ACP samples; Dr David Sherman for thoughtful discussions on ACP; Dr John Cronan for insight to fatty acid metabolism; Dr Barry Bochner for details of Biolog reagents; and Dr Charles Rock for the generous gift of ACP-specific antibody. This work was supported by the Cellular and Molecular Biology Training Program, the University of Michigan Rackham Predoctoral Fellowship, and NIH Grant 2 R01 Al44212.

\section{References}

Abdelrahman, Y.M., and Belland, R.J. (2005) The Chlamydial developmental cycle. FEMS Microbiol Rev 29: 949-959.

Alli, O.A.T., Gao, L.-Y., Pedersen, L.L., Zink, S., Radulic, M., Doric, M., and Abu Kwaik, Y. (2000) Temporal pore formation-mediated egress from macrophages and alveolar epithelial cells by Legionella pneumophila. Infect Immun 68: 6431-6440.

Archuleta, R.J., Hoppes, P.Y., and Primm, T.P. (2005) Mycobacterium avium enters a state of metabolic dormancy in response to starvation. Tuberculosis 85: 147-158.

Bachman, M.A., and Swanson, M.S. (2001) RpoS co-operates with other factors to induce Legionella pneumophila virulence in the stationary phase. Mol Microbiol 40: 1201-1214.

Bachman, M.A., and Swanson, M.S. (2004a) Genetic evidence that Legionella pneumophila RpoS modulates expression of the transmission phenotype in both the exponential phase and the stationary phase. Infect Immun 72: 2468-2476.

Bachman, M.A., and Swanson, M.S. (2004b) The LetE protein enhances expression of multiple LetA/LetSdependent transmission traits by Legionella pneumophila. Infect Immun 72: 3284-3293.

Battesti, A., and Bouveret, E. (2006) Acyl carrier protein/ SpoT interaction, the switch linking SpoT-dependent stress response to fatty acid metabolism. Mol Microbio/ 62: 10481063.

Berger, K.H., and Isberg, R.R. (1993) Two distinct defects in intracellular growth complemented by a single genetic locus in Legionella pneumophila. Mol Microbiol 7: 7-19.

Berger, K.H., Merriam, J.J., and Isberg, R.R. (1994) Altered intracellular targeting properties associated with mutations in the Legionella pneumophila dotA gene. Mol Microbiol 14: 809-822.

Bohnhoff, M., Miller, C.P., and Martin, W.R. (1964) Resistance of mouse's intestinal tract to experimental Salmonella infection. I. Factors which interfere with the initiation of infection by oral inoculation. J Exp Med 120: 805-816.

Boucher, P.E., Menozzi, F.D., and Locht, C. (1994) The modular architecture of bacterial response regulators: insights into the activation mechanism of the BvgA transactivator of Bordetella pertussis. J Mol Biol 241: 363-377.

Broich, M., Rydzewski, K., McNealy, T.L., Marre, R., and Flieger, A. (2006) The global regulatory proteins LetA and RpoS control phospholipase A, lysophospholipase A, acyltransferase, and other hydrolytic activities of Legionella pneumophila JR32. J Bacteriol 188: 1218-1226. 
Bruggemann, H., Hagman, A., Jules, M., Sismeiro, O., Dillies, M.A., Gouyette, C., et al. (2006) Virulence strategies for infecting phagocytes deduced from the in vivo transcriptional program of Legionella pneumophila. Cell Microbiol 8: 1228-1240.

Buttke, T.M., and Ingram, L.O. (1978) Inhibition of unsaturated fatty acid synthesis in Escherichia coli by the antibiotic cerulenin. Biochemistry 17: 5282-5286.

Byrne, B., and Swanson, M.S. (1998) Expression of Legionella pneumophila virulence traits in response to growth conditions. Infect Immun 66: 3029-3034.

Cashel, M. (1969) The control of ribonucleic acid synthesis in Escherichia coli. J Biol Chem 244: 3133-3141.

Cashel, M. (1994) Detection of (p)ppGpp accumulation patterns in Escherichia coli mutants. In Adolph, K.W. (ed.). Methods in Molecular Genetics, Vol. 3. Molecular Microbiology Techniques, Part A. New York: Academic Press, pp. 341-356.

Cazalet, C., Rusniok, C., Bruggemann, H., Zidane, N., Magnier, A., Ma, L., et al. (2004) Evidence in the Legionella pneumophila genome for exploitation of host cell functions and high genome plasticity. Nat Genet 36: 1165-1173.

Chien, M., Morozova, I., Shi, S., Sheng, H., Chen, J., Gomez, S.M., et al. (2004) The genomic sequence of the accidental pathogen Legionella pneumophila. Science 305: 19661968.

Cook, G.A., King, M.T., and Veech, R.L. (1978) Ketogenesis and malonyl coenzyme $A$ content of isolated rat hepatocytes. J Biol Chem 253: 2529-2531.

Dalebroux, ZD, Edwards, R.L., and Swanson M.S. (2009) SpoT governs Legionella pneumophila differentiation in host macrophages. Mol Microbiol 71: 640-658.

DiRusso, C.C., and Nystrom, T. (1998) The fats of Escherichia coli during infancy and old age: regulation by global regulators, alarmones and lipid intermediates. Mol Microbiol 27: 1-8.

Faulkner, G., and Garduno, R.A. (2002) Ultrastructural analysis of differentiation in Legionella pneumophila. J Bacteriol 184: 7025-7041.

Fernandez-Moreira, E., Helbig, J.H., and Swanson, M.S. (2006) Membrane vesicles shed by Legionella pneumophila inhibit fusion of phagosomes with lysosomes. Infect Immun 74: 3285-3295.

Fettes, P.S., Forsbach-Birk, V., Lynch, D., and Marre, R. (2001) Overexpression of a Legionella pneumophila homologue of the E. coli regulator csrA affects cell size, flagellation and pigmentation. Int J Med Microbiol 291: 353-360.

Fields, B.S., Benson, R.F., and Besser, R.E. (2002) Legionella and Legionnaires' disease: 25 years of investigation. Clin Microbiol Rev 15: 506-526.

Flieger, A., Gong, S., Faigle, M., Mayer, H.A., Kehrer, U., MuBotter, J., et al. (2000) Phospholipase A secreted by Legionella pneumophila destroys alveolar surfactant phospholipids. FEMS Microbiol Lett 188: 129-133.

Garduno, R.A., Garduno, E., Hiltz, M., and Hoffman, P.S. (2002) Intracellular growth of Legionella pneumophila gives rise to a differentiated form dissimilar to stationaryphase forms. Infect Immun 70: 6273-6283.

Gong, L., Takayama, K., and Kjelleberg, S. (2002) Role of spoT-dependent ppGpp accumulation in the survival of light-exposed starved bacteria. Microbiol 148: 559-570.
Grabner, R., and Meerbach, W. (1991) Phagocytosis of surfactant by alveolar macrophages in vitro. Am J Physiol 261: L472-L477.

Hammer, B.K., and Swanson, M.S. (1999) Co-ordination of Legionella pneumophila virulence with entry into stationary phase by ppGpp. Mol Microbiol 33: 721-731.

Hammer, B.K., Tateda, E.S., and Swanson, M.S. (2002) A two-component regulator induces the transmission phenotype of stationary-phase Legionella pneumophila. Mol Microbiol 44: 107-118.

Heath, R.J., and Rock, C.O. (1995) Regulation of malonylCoA metabolism by acyl-acyl carrier protein and $\beta$-ketoacyl-acyl carrier protein synthases in Escherichia coli. J Biol Chem 270: 15531-15538.

Heinzen, R.A., Hackstadt, T., and Samuel, J.E. (1999) Developmental biology of Coxiella burnetii. Trends Microbiol 7: $149-154$.

Hood, M.A., Guckert, J.B., White, D.C., and Deck, F. (1986) Effect of nutrient deprivation on lipid, carbohydrate, DNA, RNA, and protein levels in Vibrio cholerae. Appl Environ Microbiol 52: 788-793.

Jackowski, S., and Rock, C.O. (1983) Ratio of active to inactive forms of acyl carrier protein in Escherichia coli. J Biol Chem 258: 15186-15191.

Jacobi, S., Schade, R., and Heuner, K. (2004) Characterization of the alternative sigma factor $\sigma^{54}$ and the transcriptional regulator FleQ of Legionella pneumophila, which are both involved in the regulation cascade of flagellar gene expression. J Bacteriol 186: 2540-2547.

Joshi, A.D., Sturgill-Koszycki, S., and Swanson, M.S. (2001) Evidence that Dot-dependent and -independent factors isolate the Legionella pneumophila phagosome from the endocytic network in mouse macrophages. Cell Microbiol 3: 99-114.

Lawhon, S.D., Maurer, R., Suyemoto, M., and Altier, C. (2002) Intestinal short-chain fatty acids alter Salmonella typhimurium invasion gene expression and virulence through BarA/SirA. Mol Microbiol 46: 1451-1464.

Lynch, D., Fieser, N., Gloggler, K., Forsbach-Birk, V., and Marre, R. (2003) The response regulator LetA regulates the stationary-phase stress response in Legionella pneumophila and is required for efficient infection of Acanthamoeba castellanii. FEMS Microbiol Lett 219: 241248.

McCleary, W.R., Stock, J.B., and Ninfa, A.J. (1993) Is acetyl phosphate a global signal in Escherichia coli? J Bacteriol 175: 2793-2798.

McCune, S.A., and Harris, R.A. (1979) Mechanism responsible for 5-(tetradecyloxy)-2-furoic acid inhibition of hepatic lipogenesis. J Biol Chem 254: 10095-10101.

McNealy, T.L., Forsbach-Birk, V., Shi, C., and Marre, R. (2005) The Hfq homolog in Legionella pneumophila demonstrates regulation by LetA and RpoS and interacts with the global regulator CsrA. J Bacteriol 187: 15271532.

Magnuson, K., Jackowski, S., Rock, C.O., and Cronan, J.E., Jr (1993) Regulation of fatty acid biosynthesis in Escherichia coli. Microbiol Rev 57: 522-542.

Magnusson, L.U., Farewell, A., and Nystrom, T. (2005) ppGpp: a global regulator in Escherichia coli. Trends Microbiol 13: 236-242. 
Molofsky, A.B., and Swanson, M.S. (2003) Legionella pneumophila CsrA is a pivotal repressor of transmission traits and activator of replication. Mol Microbiol 50: 445461.

Molofsky, A.B., Shetron-Rama, L.M., and Swanson, M.S. (2005) Components of the Legionella pneumophila flagellar regulon contribute to multiple virulence traits, including lysosome avoidance and macrophage death. Infect Immun 73: 5720-5734.

Molofsky, A.B., Byrne, B.G., Whitfield, N.N., Madigan, C.A., Fuse, E.T., Tateda, K., and Swanson, M.S. (2006) Cytosolic recognition of flagellin by mouse macrophages restricts Legionella pneumophila infection. J Exp Med 203: 10931104.

Omura, S. (1976) The antibiotic cerulenin, a novel tool for biochemistry as an inhibitor of fatty acid synthesis. Bacteriol Rev 40: 681-697.

Panek, E., Cook, G.A., and Cornell, N.W. (1977) Inhibition by 5-(tetradecyloxy)-2-furoic acid of fatty acid and cholesterol synthesis in isolated rat hepatocytes. Lipids 12: 814-818.

Pizer, E.S., Thupari, J., Han, W.F., Pinn, M.L., Chrest, F.J., Frehywot, G.L., et al. (2000) Malonyl-coenzyme-A is a potential mediator of cytotoxicity induced by fatty-acid synthase inhibition in human breast cancer cells and xenografts. Cancer Res 60: 213-218.

Post-Beittenmiller, D., Jaworski, J.G., and Ohlrogge, J.B. (1991) In vivo pools of free and acylated acyl carrier proteins in spinach. J Biol Chem 266: 1858-1865.

Purevdorj-Gage, B., Costerton, W.J., and Stoodley, P. (2005) Phenotypic differentiation and seeding dispersal in nonmucoid and mucoid Pseudomonas aeruginosa biofilms. Microbiology 151: 1569-1576.

Ren, T., Zamboni, D.S., Roy, C.R., Dietrich, W.F., and Vance, R.E. (2006) Flagellin-deficient Legionella mutants evade caspase-1- and Naip5-mediated macrophage immunity. PLoS Pathog 2: e18.

Rock, C.O., and Cronan, J.E., Jr (1981) Acyl carrier protein from Escherichia coli. Methods Enzymol 71: 341-351.

Rowbotham, T.J. (1986) Current views on the relationships between amoebae, legionellae and man. Isr J Med Sci 22: 678-689.

Samuel, J.E., Kiss, K., and Varghees, S. (2003) Molecular pathogenesis of Coxiella burnetii in a genomics era. Ann N Y Acad Sci 990: 653-663.

Sauer, J.D., Bachman, M.A., and Swanson, M.S. (2005) The phagosomal transporter A couples threonine acquisition to differentiation and replication of Legionella pneumophila in macrophages. Proc Natl Acad Sci USA 102: 9924-9929.

Schujman, G.E., Altabe, S., and de Mendoza, D. (2008) A malonyl-CoA-dependent switch in the bacterial response to a dysfunction of lipid metabolism. Mol Microbiol 68: 987-996.

Segal, G., Feldman, M., and Zusman, T. (2005) The Icm/Dot type-IV secretion systems of Legionella pneumophila and Coxiella burnetii. FEMS Microbiol Rev 29: 65-81.

Seyfzadeh, M., Keener, J., and Nomura, M. (1993) spoTdependent accumulation of guanosine tetraphosphate in response to fatty acid starvation in Escherichia coli. Proc Natl Acad Sci USA 90: 11004-11008.

Shi, C., Forsbach-Birk, V., Marre, R., and McNealy, T.L. (2006) The Legionella pneumophila global regulatory protein LetA affects DotA and Mip. Int J Med Microbiol 296: 15-24.

Srivatsan, A., and Wang, J.D. (2008) Control of bacterial transcription, translation and replication by (p)ppGpp. Curr Opin Microbiol 11: 100-105.

Stone, B.J., and Abu Kwaik, Y. (1999) Natural competence for DNA transformation by Legionella pneumophila and its association with expression of type IV pili. J Bacteriol 181: 1395-1402.

Sturgill-Koszycki, S., and Swanson, M.S. (2000) Legionella pneumophila replication vacuoles mature into acidic, endocytic organelles. J Exp Med 192: 1261-1272.

Swanson, M.S., and Isberg, R.R. (1995) Association of Legionella pneumophila with the macrophage endoplasmic reticulum. Infect Immun 63: 3609-3620.

Ulrich, A.K., de Mendoza, D., Garwin, J.L., and Cronan, J.E., Jr (1983) Genetic and biochemical analyses of Escherichia coli mutants altered in the temperature-dependent regulation of membrane lipid composition. J Bacteriol 154: 221230.

Vance, D., Goldberg, I., Mitsuhashi, I., Bloch, K., Omura, S., and Nomura, S. (1972) Inhibition of fatty acid synthetases by the antibiotic cerulenin. Biochem Biophys Res Commun 48: 649-656.

Vinzing, M., Eitel, J., Lippmann, J., Hocke, A.C., Zahlten, J., Slevogt, H., et al. (2008) NAIP and Ipaf control Legionella pneumophila replication in human cells. J Immunol 180: 6808-6815.

Warren, W.J., and Miller, R.D. (1979) Growth of Legionnaires disease bacterium (Legionella pneumophila) in chemically defined medium. J Clin Microbiol 10: 50-55.

Watarai, M., Derre, I., Kirby, J., Growney, J.D., Dietrich, W.F., and Isberg, R.R. (2001) Legionella pneumophila is internalized by a macropinocytotic uptake pathway controlled by the Dot/lcm system and the mouse Lgn1 locus. J Exp Med 194: 1081-1096.

Wieland, H., Faigle, M., Lang, F., Northoff, H., and Neumeister, B. (2002) Regulation of the Legionella mip-promotor during infection of human monocytes. FEMS Microbiol Lett 212: $127-132$.

Wieland, H., Ullrich, S., Lang, F., and Neumeister, B. (2005) Intracellular multiplication of Legionella pneumophila depends on host cell amino acid transporter SLC1A5. Mol Microbiol 55: 1528-1537.

Wolfe, A.J. (2005) The acetate switch. Micro Mol Biol Rev 69: $12-50$.

Zhou, W., Simpson, P.J., McFadden, J.M., Townsend, C.A., Medghalchi, S.M., Vadlamudi, A., et al. (2003) Fatty acid synthase inhibition triggers apoptosis during $S$ phase in human cancer cells. Cancer Res 63: 7330-7337.

Zusman, T., Gal-Mor, O., and Segal, G. (2002) Characterization of a Legionella pneumophila relA insertion mutant and toles of RelA and RpoS in virulence gene expression. J Bacteriol 184: 67-75. 